\title{
Phase-Transition Regularities in Critical Constants, Fusion Temperatures and Enthalpies of Chemically Similar Chainlike Structures
}

\begin{abstract}
Alexandru T. Balaban, ${ }^{[a]}$ Douglas J. Klein, ${ }^{[a]}$ Norman H. March, ${ }^{[b, c]}$ Mario P. Tosi, ${ }^{[d]}$ and M. Ausloos ${ }^{[e]}$

In view of Michele Parrinello's current interests bridging Chemistry and Physics, evidenced by the jointly published book: Collective Effects in Solids and Liquids, ${ }^{[2]}$ we felt it might be of interest to revisit some "cooperative phenomena" in one clearly chemical area, namely, critical constants, fusion temperature and fusion enthalpy of $n$-alkanes, and one area nearer to the interests of physicists studying the liquid state, namely, the heavy fluid alkali metals $\mathrm{Rb}$ and $\mathrm{Cs}$. Since Michele's work has always stressed the importance of the interaction between theory and experiment, we need make no apologies for focusing dominantly on experimental regularities in the systems referred to above. However, some modest theoretical interpretation is then offered, which seems to afford a degree of insight into the experimental regularities, which include fusion temperatures and fusion enthalpies, as well as critical constants.
\end{abstract}

\section{Critical Temperatures of $\boldsymbol{n}$-Alkanes}

Let us begin the discussion of cooperative phenomena by recording the variation found experimentally of the critical temperature $T_{c}$ versus $n$ for linear alkanes $\mathrm{C}_{n} \mathrm{H}_{2 n+2}$. Data for $n$-alkanes are presented in Table 1. The data for $T_{\mathrm{c}}$ in Table 1 show the experimental results spanning the range of $n$ from 5 to $16,^{[3]}$ from 17 to $24,{ }^{[4 \mathrm{~b}]}$ and beyond $24 .^{[4 \mathrm{a}]}$ The continuous curve follows a plot of the data ranging from $n=5$ to $n=16$ given in the earlier study involving one of us. ${ }^{[1]}$ This investigation, which considered a variety of models, pinpointed that based on Wertheim's thermodynamic perturbation model ${ }^{[5]}$ (see also ref. [6]). The prediction of this model for large values of $n$ takes the form of Equation (1):

$T_{c}(n)=T_{c}(\infty)+b n^{-1 / 2}+c n^{-1}+\ldots$

[a] Prof. A. T. Balaban, Prof. D. J. Klein Texas A\&M University at Galveston 5007 Avenue U, Galveston, TX 77551 (USA) Fax: $(+1)$ 409-740-4787 E-mail:balabana@tamug.edu

[b] Prof. N. H. March University of Antwerp, Department of Physics, Antwerp (Belgium)

[c] Prof. N. H. March Theoretical Chemistry Department, Oxford University, Oxford (UK)

[d] Prof. M. P. Tosi Scuola Normale Superiore, Pisa (Italy)

[e] Dr. M. Ausloos Physics Institute B5, 4000 Liège (Belgium) 


\begin{tabular}{|ccccc|}
\hline \multicolumn{5}{|c|}{ Table 1. Data for $n$-alkanes $\mathrm{C}_{n} \mathrm{H}_{2 n+2}{ }^{[\text {[a] }}$. } \\
$n$ & $T_{\text {fus }}[\mathrm{K}]$ & Normal b.p. $\left[{ }^{\circ} \mathrm{C}\right]$ & $T_{\mathrm{c}}[\mathrm{K}]$ & Fusion enthalpy $\left[\mathrm{Jmol}^{-1}\right]$ \\
\hline 1 & 90.7 & -161.6 & 190.6 & 940 \\
2 & 90.1 & -88.6 & 305.3 & 2859 \\
3 & 85.5 & -42.2 & 369.8 & 3527 \\
4 & 134.8 & -0.5 & 425.1 & 4661 \\
5 & 143.4 & 36.1 & 469.7 & 8405 \\
6 & 177.8 & 68.8 & 507.6 & 13124 \\
7 & 182.5 & 98.4 & 540.2 & 14061 \\
8 & 216.3 & 125.7 & 568.7 & 20707 \\
9 & 219.6 & 149.5 & 594.6 & 15465 \\
10 & 243.5 & 173 & 617.7 & 28698 \\
11 & 247.7 & 195.8 & 639 & 22225 \\
12 & 263.6 & 214.5 & 658 & 36755 \\
13 & 267.6 & 234 & 675 & 28485 \\
14 & 279.1 & 252.5 & 693 & 45030 \\
15 & 283.1 & 270.5 & 708 & 34574 \\
16 & 291.2 & 287 & 723 & 53332 \\
17 & 294.9 & 302 & 736 & 40124 \\
18 & 301.2 & 317 & 747 & 61306 \\
19 & 304.9 & 329.9 & 755 & 45580 \\
20 & 309.5 & 344 & 768 & 69730 \\
21 & 313.2 & 356.5 & 778 & 47697 \\
22 & 317.5 & 368.6 & 786 & \\
23 & 320.9 & 380 & 790 & 50863 \\
24 & 326.1 & 391.3 & 800 & \\
25 & 327.1 & & & 57122 \\
26 & & & 816 & \\
27 & 332.4 & & 824 & 62024 \\
28 & & & 66939 \\
29 & 336.8 & & 843 & \\
30 & & & & \\
\hline$[a]$ Data collected from refs. $[3,4,12]$. & & \\
\hline
\end{tabular}

The smooth curve for $T_{\mathrm{c}}$ versus $n$ according to the data presented in Table 1 has the form of Equation (1), with $T_{c}(\infty)=$ $1290 \mathrm{~K}, b=-2830 \mathrm{~K}$, and $c=2227 \mathrm{~K} \cdot{ }^{[1]}$ The agreement between the Wertheim model $n$-dependence, of course truncated beyond order $n^{-1}$ displayed in Equation (1), is truly remarkable, though it is a three-parameter fit of only a few experimental points. A similar relationship with different parameters was advocated by Nikitin et al.. ${ }^{[4 b]} T_{c}(\infty)=1258.73 \mathrm{~K}, b=-2654.38 \mathrm{~K}$, and $c=1992 \mathrm{~K}$. Taking into account that for $n>20$ the reduced melting temperature (i.e., the ratio between $T_{\text {fus }}$ and $T_{\mathrm{c}}$ ) is practically constant and approximately equal to 0.404 (see also Figure 3 below) leaves the problem to predict the critical temperature of an infinite polyethylene chain. Amorós $s^{[4 a]}$ using equations with more terms in a power series proposed the value $T_{\mathrm{c}}(\infty)=1026.2 \mathrm{~K}$

Chickos and co-workers ${ }^{[7]}$ used Ambrose's Equation (2) for the critical temperature of $n$-alkanes: $:^{[8]}$

$T_{\mathrm{c}}(n)=T_{\mathrm{b}}(n)+T_{\mathrm{b}}(n) /[c+d(n+2)]$

where $c$ and $d$ are constants. The normal boiling temperature $\left(T_{\mathrm{b}}\right)$ can be fitted to a similar hyperbolic function, Equation (3):

$T_{\mathrm{c}}(n)=T_{\mathrm{c}}(\infty)\left[1-1 /\left(a_{\mathrm{c}} n+b_{\mathrm{c}}\right)\right]$

where $a_{\mathrm{c}}$ and $b_{\mathrm{c}}$ are constants. Hence, as $n \rightarrow \infty, T_{\mathrm{c}}$ and $T_{\mathrm{b}}$ would tend towards one another, $T_{\mathrm{c}}(\infty)=T_{\mathrm{b}}(\infty)=1217 \pm$ $246 \mathrm{~K}^{\left[{ }^{[7]}\right.}$

A QSAR study of the parameters in the Antoine equation for critical constants for all alkane isomers with two through nine carbon atoms in terms of topological indices was given earlier by one of us. ${ }^{[9]}$

\section{Fusion Temperatures and Fusion Enthalpies for $n$-Alkanes}

We turn next to consider data on fusion temperatures and fusion enthalpies for linear alkanes $\mathrm{C}_{n} \mathrm{H}_{2 n+2}$. The normal (or linear) alkanes $\mathrm{C}_{n} \mathrm{H}_{2 n+2}$ have fusion temperatures that tend asymptotically towards a finite limit. For linear polyethylene, this limit is around $T_{\text {fus }}(\infty) \cong 141{ }^{\circ} \mathrm{C}=414 \mathrm{~K} \cdot{ }^{[10]}$ Crystallographic data reveal that in the solid state the linear chains (with lengths up to about $n=30$ ) are extended in the all-trans conformation, though in finer detail different space-group symmetries arise. However, for much longer chains, folded conformations are possible, and the chain flexibility allows many different conformations in the fluid state. ${ }^{[11]}$ The normal boiling points of $n$-alkanes increase smoothly with increasing $n$; of course, unlike temperatures of fusion that can be measured for $n \rightarrow \infty$, boiling points at normal pressure for alkanes with $n>$ 25 become so elevated that $\mathrm{C}-\mathrm{H}$ or $\mathrm{C}-\mathrm{C}$ bond splitting occurs, resulting in dehydrogenation and/or cracking.

Data in Table 1 for phase transitions are from refs. $[4,12]$ One can observe from Table 1 and Figure 1 and 2 the wellknown odd- $n /$ even- $n$ alternation of melting points (fusion tem-

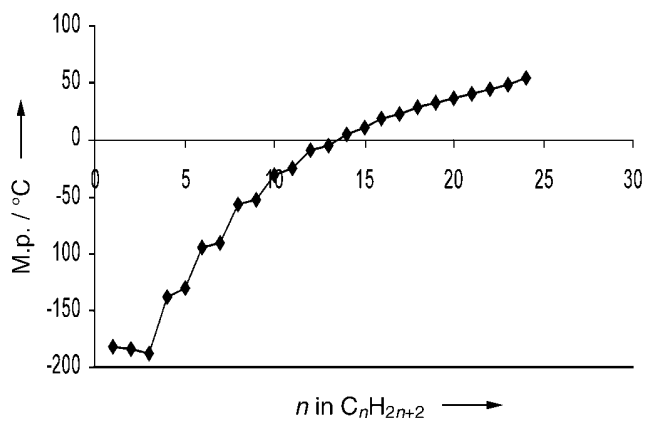

Figure 1. Plot of fusion temperatures (melting points) versus $n$ for linear alkanes $\mathrm{C}_{n} \mathrm{H}_{2 n+2}$.

peratures, $T_{\text {fus }}$ in $\left.\mathrm{K}\right)$ and fusion enthalpies $\left(\Delta H_{\text {fus }}\right)$ in $n$-alkanes, respectively. Whereas the former alternation becomes attenuated with increasing $n$ and is no longer detectable for $n>16$, the latter alternation leads to two diverging variations with a higher slope for even- $n$ linear alkanes (which have an almost constant increment of about $8.2 \mathrm{~kJ} \mathrm{~mol}^{-1}$ for each $\mathrm{CH}_{2}-\mathrm{CH}_{2}$ fragment) than for odd- $n$ alkanes (which for $n$ varying from $n=9$ to $n=29$ have increments centered around 6.7 to $3 \mathrm{~kJ} \mathrm{~mol}^{-1}$ for each $\mathrm{CH}_{2}-\mathrm{CH}_{2}$ fragment). It was reported ${ }^{[13]}$ that for higher alkanes the enthalpy of fusion was $3.93 \pm$ $0.13 \mathrm{~kJ} \mathrm{~mol}^{-1}$ of $\mathrm{CH}_{2}$, and the entropy of fusion was 7.7$9.1 \mathrm{JK}^{-1} \mathrm{~mol}^{-1}$ of $\mathrm{CH}_{2}$. 


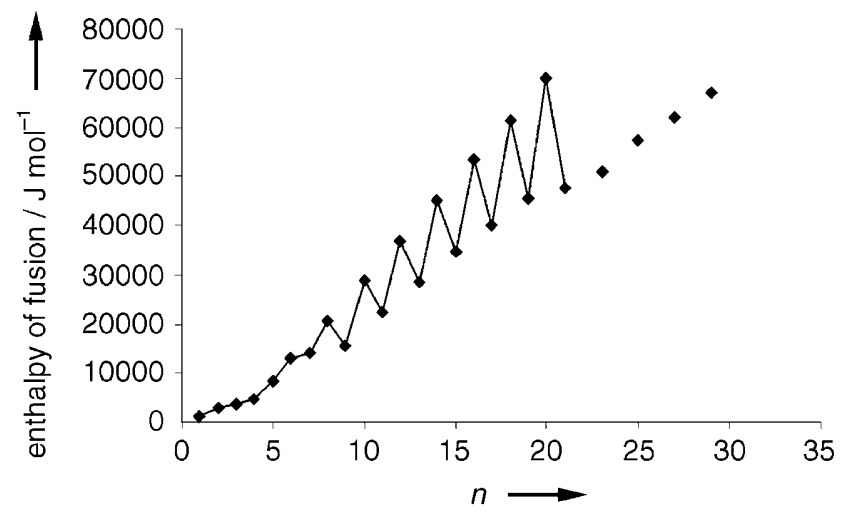

Figure 2. Plot of enthalpies of fusion versus $n$ for linear alkanes $C_{n} \mathrm{H}_{2 n+2}$.

Boese and co-workers in a series of studies on "The melting point alternation in $n$-alkanes and derivatives" ${ }^{1[14]}$ proposed an explanation of this alternation for $n<10$ in terms of a geometrical model: the even- $n$ and odd- $n$ members of the triclinic $n$ alkanes have unlike intermolecular interactions between the end (methyl) groups because of a different packing. The geometrical model envisions even- $n$ members as modified parallelograms, and odd- $n$ members as modified trapezoids. The packing of the former (but not of the latter) allows an offset which reduces the repulsions between the end groups. For larger alkanes, up to $n \cong 21$, there is an alternation between two different crystal structures with the alkane chains in alternating lateral relations. ${ }^{[15]}$ For $n \geq 2$, the crystal structure remains the "same", though different solid rotator phases are stable just preceding melting. ${ }^{[16]}$ The different crystal structures, with different rotator phases, evidently relieve different degrees of "molecular freedom" prior to melting, so that rather different entropies of fusion and consequent melting points arise (Figure 2).

Alkanes with various $n$ values also present alternating densities, refractive indexes and solubilities. ${ }^{[17]}$ The perdeuterated congeners always have lower melting points that differ by about $1 \mathrm{~K}$ for the small- or medium-sized alkanes, and this difference increases up to about 4.8 for linear polyethylene. ${ }^{[18]}$ The higher cohesion shown in the solid phase by the even- $n$ linear alkanes relative to the odd- $n$ linear alkanes is paralleled by a similar behavior of $\alpha, \omega$-bifunctional derivatives such as diols, dithiols, dicarboxylic acids, diesters, diamines, and diamides. ${ }^{[14,19]}$ Various models have been proposed for $T_{\text {fus }}$ of orthorhombic normal alkanes, including Broadhurst's equation, Equation (4)::[20]

$T_{\text {fus }}(n)=T_{\text {fus }}(\infty)(n+r) /(n+s)$

with $T_{\text {fus }}(\infty)=414.3 \mathrm{~K}, r=-1.5, s=5.0$. A related approach used the Gibbs-Thomson equation to explain the melting temperature of lamellar polyethylene crystals. ${ }^{[20 c]}$ Properties not involving the solid state (e.g., $T_{\mathrm{b}}, \Delta H_{\text {vap }}$ etc.) typically exhibit smooth behavior as a function of the linear alkane's length.

A plot of $T_{c}$ versus the melting point for $n$-alkanes with 3 through 29 carbon atoms is shown in Figure 3. The slope of

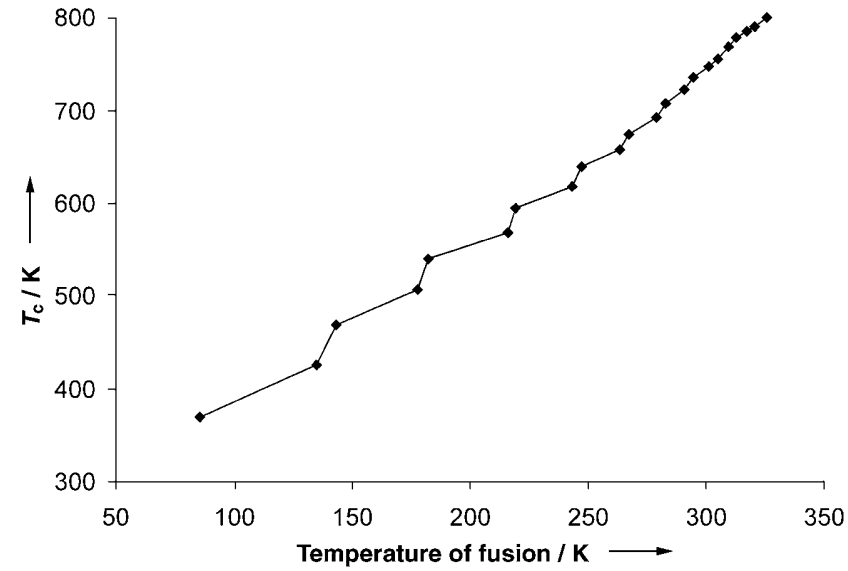

Figure 3. Plot of critical temperatures versus melting points for $n$-alkanes starting with propane $(n=3)$ through $\mathrm{C}_{29} \mathrm{H}_{60}$.

the straight line fitted through the points is close to 2, in agreement with the linking "coordination number" of 2 of all carbon atoms except for the end-groups; compare Equation (6) for fluid alkali metals given below.

\section{Critical Constants of Heavy Fluid Alkalis, Rb and Cs}

Neutron diffraction experiments ${ }^{[21]}$ carried out on a number of different thermodynamic states of liquid $\mathrm{Rb}$ and $\mathrm{Cs}$ along the liquid-vapor coexistence curves have allowed the near-neighbor distance and the first coordination number $z$ to be extracted from the structural data. The values of the near-neighbor distance remained fairly constant along the liquid-vapor coexistence curves of both $\mathrm{Rb}$ and $\mathrm{Cs}^{\left[{ }^{[22]}\right.}$ Thus, the lowering of the density $(d)$ as one goes from the melting point to the critical point must come dominantly from the reduction of the coordination number $z .^{[23]}$ One of $u s^{[24]}$ fitted the neutron diffraction data for the coordination number $z$ by Equation (5):

$d=a z+b$

where $a=230 \mathrm{~kg} \mathrm{~m}^{-3}$ and $b=-80 \mathrm{~kg} \mathrm{~m}^{-3}$. This fit then leads to a coordination number near to 2 at the critical point.

Freeman and March $^{[24]}$ have compared the (likely) chains in Cs fluid metal near the critical temperature $T_{c}$ with results for small coverage of Cs adsorbed on surfaces of some semiconductors. In particular, the investigation of Whitman et al. ${ }^{[25]}$ suggested chains of about $1000 \AA$ in length, which should roughly equate to a number of monomers $n$ in the chain of about 150 .

Probably, in marked contrast with the $n$-alkanes, the length of the (assumed) chains in, say, $\mathrm{Rb}$ may require knowledge of a certain fairly disperse distribution within a given thermodynamic state. Assuming that as criticality is approached, a certain length becomes dominant, characterized say by mean monomer numbers $n_{c}^{\mathrm{Rb}}$ and $n_{c}^{\mathrm{cs}}$, it is of interest to know whether the clearly observable trends (see Table 2 ) in the critical constants of the fluid alkali metals (we suggest particularly $\mathrm{K}, \mathrm{Rb}$, 


\begin{tabular}{|lllll|}
\hline \multicolumn{6}{|l|}{ Table 2. Data for alkali metals. } \\
Element & $P_{\mathrm{c}}[\mathrm{mPa}]$ & $10^{4} V_{\mathrm{c}}\left[\mathrm{m}^{3} \mathrm{~mol}^{-1}\right]$ & $T_{\mathrm{c}}[\mathrm{K}]$ & $P_{\mathrm{c}} V_{\mathrm{c}}\left[10^{-3} \mathrm{eV}\right]$ \\
\hline $\mathrm{Li}$ & 30.4 & 0.588 & 3344 & 17.9 \\
$\mathrm{Na}$ & 25.2 & 1.09 & 2497 & 27.5 \\
$\mathrm{~K}$ & 15.9 & 2.04 & 2239 & 32.5 \\
$\mathrm{Rb}$ & 12.5 & 2.93 & 2017 & 36.5 \\
$\mathrm{Cs}$ & 9.3 & 3.51 & 1924 & 32.5 \\
\hline
\end{tabular}

and Cs) can be described by laws similar to those appropriate for $n$-alkanes.

From the final column of Table 2, we note (see also ref. [1]) that the approximate constancy of the product $P_{c} V_{c}$ (except for Li) would follow Wertheim's asymptotic prediction for really long chains, if these chains were about the same length from $\mathrm{Na}$ to $\mathrm{Cs}$

\section{Summary and Future Directions}

Empirical regularities are marked in the $n$-alkane series for both fusion temperature and enthalpy, and critical constants. In particular, Wertheim's asymptotic prediction for long chains embodied in Equation (1) fits the experimental data on critical temperature $T_{\mathrm{c}}(n)$ very well indeed, over the range indicated in Table 1.

As for fluid alkali metals, these may form chains as their critical points are approached, supporting experimental evidence being cited above for $\mathrm{Rb}$ and $\mathrm{Cs}$. We note here that the melting temperature obeys the relationship in Equation (6) (see also refs. $[25,27])$ :

$T_{\mathrm{m}}=A T_{\mathrm{c}}+B$

where $A \cong 1 / 8$, which is the inverse of the coordination number for the body-centered cubic lattice for the solid alkali metals. Here with the absence of chains in the solid state the situation may be somewhat simpler than that involving the $n$-alkanes.

As to future directions for fruitful studies, a significant problem for linear alkanes, deserving further investigation, is to predict the critical temperature of an infinite polyethylene chain, to confirm or refine the proposal of Amorós. ${ }^{[4]}$ The study in ref. [9] invoking topological indices for critical constants of alkane isomers seems also worthy of expansion in the future. Finally, further studies, both from experiment and theory, seem promising relating to more detailed structural information especially on the heavy fluid alkalis $\mathrm{Rb}$ and Cs. Can chainlike structures be established beyond reasonable doubt, and can the distribution of chain lengths be estimated if chains are indeed confirmed, as for Cs adsorbed on some semiconductor surfaces? As mentioned above, the absence of chains in the solid state may simplify further theoretical analysis compared with that obtaining for $n$-alkanes.

\section{Acknowledgements}

D.J.K. acknowledges support (through grant BD-0894) from the Welch Foundation of Houston, Texas.

Keywords: alkali metals • alkanes - critical temperatures fusion enthalpies $\cdot$ fusion temperatures

[1] F. E. Leys, N. H. March, V. E. Van Doren, Phys. Chem. Liq. 2002, 40, $143-$ 157.

[2] N. H. March, M. Parrinello, Collective Effects in Solids and Liquids, Hilger, Bristol, 1982.

[3] M. J. Anselme, M. Gude, A. S. Teja, Fluid Phase Equilibria, 1998, 57, 317 326.

[4] a) J. Amorós, Phys. Chem. Liq. 2002, 40, 269-275; b) Handbook of Chemistry and Physics, 83rd Edition, CRC Press, Boca Raton, 2002; c) E. D. Nikitin, P. A. Pavlov, N. V. Bessonova, J. Chem. Thermodyn. 1994, 26, $177-1821$.

[5] M. S. Wertheim, J. Stat. Phys. 1984, 35, 19-34; M. S. Wertheim, J. Stat. Phys. 1984, 35, 35-47; M. S. Wertheim, J. Stat. Phys. 1986, 42, 459-476, 477-492; M. S. Wertheim, J. Chem. Phys. 1987, 87, 7323-7331.

[6] a) G. Jackson, W. G. Chapman, K. E. Gubbins, Mol. Phys. 1988, 65, 1-31; b) C. Vega, L. G. MacDowell, J. Chem. Phys. 2001, 114, 10411-10417.

[7] a) J. S. Chickos, G. Nichols, J. Chem. Eng. Data, 2001, 46, 562-573; b) J. S. Chickos, J. Chem. Eng. Data, 2004, 49, 518-526.

[8] D. Ambrose, NPL Report Chemistry No. 92, National Physical Laboratory, Middlesex, UK, 1978.

[9] A. T. Balaban, V. Feroiu, Reports Molec. Theory, 1990, 1, 133-139.

[10] a) K. H. Meyer, A. van der Wyk, Helv. Chim. Acta, 1937, 20, 1313-1320; K. H. Meyer, A. van der Wyk, Helv. Chim. Acta, 1937, 20, 1321-1330; K. H. Meyer, A. van der Wyk, Helv. Chim. Acta, 1937, 20, 1331-1334 b) C. D. Nenitzescu, S. Titeica, Studii Cercetari Chim. Acad. R. P. Romane, 1956, 4, 65-67; C. D. Nenitzescu, S. Titeica, I. Irimescu, Naturwiss. 1938, 26, 629; c) F. A. Quinn, Jr., L. Mandelkern, J. Am. Chem. Soc. 1958, 80, 3178-3182; d) P. J. Flory, A. Vrij, J. Am. Chem. Soc. 1963, 85, 3548-3553; e) J. G. Fatou, L. Mandelkern, J. Phys. Chem. 1965, 69, 417-428; f) K.-H. Illers, Eur. Polym. J. 1974, 10, $911-916$.

[11] A. T. Balaban, Rev. Roum. Chim. 1976, 21, 1049-1071.

[12] a) V. Chevalier, M. Bouroukba, D. Petitjean, D. Barth, P. Dupuis, M. Dirand, J. Chem. Eng. Data, 2001, 46, 1114-1122; b) M. Dirand, M. Bouroukba, A.-J. Briard, V. Chevalier, D. Petitjean, J.-P. Corriou, J. Chem. Thermodyn. 2002, 34, 1255-1277.

[13] M. J. M. Van Oort and M. A. White, Thermochim. Acta, 1985, 86, 1-6.

[14] a) R. Boese, H.-C. Weiss, D. Bläser, Angew. Chem. 1999, 111, 1042-1045; Angew. Chem. Int. Ed. 1999, 38, 918-922; b) V. R. Thalladi, R. Boese, H. C. Weiss, J. Am. Chem. Soc. 2000, 122, 1186-1190; c) V. R. Thalladi, M. Nüsse, R. Boese, J. Am. Chem. Soc. 2000, 122, 9227-9236; d) V. R. Thalladi, R. Boese, H.-C. Weiss, Angew. Chem. 1999, 112, 942-946; Angew. Chem. Int. Ed. 2000, 39, 918-922.

[15] M. R. McGann, D. J. Lacks, J. Phys. Chem. 1999, B103, 2796-2802.

[16] D. Mondieig, P. Espeau, L. Robles, Y. Haget, H. A. J. Oonk, M. A. CuevasDiarte, J. Chem. Soc. Faraday Trans. 1997, 93, 3343-3346.

[17] A.-J. Briard, M. Bouroukba, D. Petitjean, M. Dirand, J. Chem. Eng. Data 2003, 48, 1574-1577.

[18] D. L. Dorset, H. L. Strauss, R. G. Snyder, J. Phys. Chem. 1991, 95, $938-$ 940.

[19] a) F. L. Breusch, E. Ulusoy, Fette, Seifen, Anstrichmittel 1964, 66, 739-742; b) F. L. Breusch, Fortschr. Chem. Forsch. 1969, 12, 119-184; c) R. Hill, E. E. Walker, J. Polym. Sci. 1948, 3, 609; d) K. Ueberreiter, V.-H. Karl, A. Altmeyer, Eur. Polym. J. 1978, 14, 1045 -1049; e) D. D. Coffmann, G. J. Berchet, W. R. Peterson, E. W. Spanagel, J. Polym. Sci. 1947, 2, 306; f) B. Wunderlich, G. Czornyj, Macromolecules, 1977, 10, 906-913.

[20] a) M. G. Broadhurst, J. Res. Natl. Bur. Stand. 1966, A70, 481-486; b) M. L. Huggins, J. Phys. Chem. 1939, 43, 1083-1098; c) G. W. H. Höhne, Polymer 2002, 43, 4689-4698.

[21] R. Winter, F. Hensel, Phys. Chem. Liq. 1989, 20, 1-15.

[22] N. H. March, M. P. Tosi, Adv. Phys. 1995, 44, 299-386. 
[23] N. H. March, Phys. Chem. Liq. 1989, 20, $241-245$; see also N. H. March, J. Math. Chem. 1990, 4, 271-293.

[24] G. R. Freeman, N. H. March, J. Phys. Chem. 1994, 98, 9486-9487.

[25] L. J. Whitman, J. A. Stroscio, R. A. Dragoset, R. J. Celotta, Phys. Rev. Lett. $1991,66,1338-1341$, and references therein.

[26] F. E. Leys, N. H. March, V. E. Van Doren, G. Straub, Solid State Commun. 2000, 113, 479-482

[27] F. E. Leys, N. H. March, M.-L. Zhang, Phys. Chem. Liquids, 2004, 42, 217 228.

Received: August 31, 2004

Published online on July 11, 2005 